British Journal of Psychiatry (1989), 154, 719-733

\title{
Correspondence
}

Editor: Ian Pullen

Contents: Taking a good history/Repetition of parasuicide/Loss and theft/The use of propofol for anaesthesia during ECT/Sex chromosomes and psychosis/ Elderly eccentrics/The Fear Questionnaire/Is globus hystericus? / Hospital suicides/Homo-erotomania/ Violence in sleep: a further diagnostic consideration/ Nosological problems/Chronic patients in acute wards/Admission trends/The mind-body problem/ Psychological-mindedness and the alexithymia construct/Illicit drug use in strength athletes.

\section{Taking a good history}

SIR: Hare's paper (Journal, October 1988, 153, 521531 ) is one of the widest-ranging attempts so far to mount a coherent argument that schizophrenia is a recent disease which arose around 1800 . Some of his evidence is extremely detailed, but we feel that many of his deductions are questionable, in the light of other historical information which may not be readily accessible to most psychiatrists. There is room here to deal with only a few.

Dr Hare mentions that descriptions of schizophrenia were rare before 1800 , and suggests that some change "of a biological kind" occurred about that time, producing a new form of the illness. This, he postulates, might have been the disorder known as 'adolescent insanity', which he argues to have been rare at the beginning and common at the end of the 19th century. In support of this he quotes Harper (1789).

However, Harper's experience of insanity in Britain must be in doubt, as he seems to have been an army surgeon serving overseas. Moreover, his statement, quoted by Hare, that it was "well known that young people are hardly ever liable to insanity, and that the attack of this malady seldom happens until an advanced period of life" is contradicted by the more reliable evidence of John Haslam, apothecary to Bethlem Hospital (Haslam, 1809), citing the statistics for Bethlem between 1784 and 1794. Out of 1664 admissions, $7 \%$ were aged between 10 and 20 , $29 \%$ between 20 and $30,32 \%$ between 30 and 40 ,
$22 \%$ between 40 and $50,8 \%$ between 50 and 60 , and $2 \%$ between 60 and 70 . Admissions to the Bicêtre for the same period show only marginal differences.

It is unclear from Dr Hare's paper whether the 'recency' hypothesis refers to schizophrenia as a whole, or to a particular subtype like the 'early onset' variety to which he refers. Appealing to different forms of a disease at different stages of an argument about its history serves to allow an infinite flexibility in the theory, and perhaps this and other features tend to render the recency hypothesis unfalsifiable.

Even if the 'subtype' issue is allowed into the debate, however, there is good evidence that it does not help the hypothesis it is supposed to serve. Statistics derived from primary sources indicate that 'adolescent insanity' was not on the increase, although Hare suggests that its growth was an important feature of the 19th century. Wilkins (1987) looked specifically at admission rates to Bethlem during this era for age groups which he considered most at risk for developing schizophrenia. His figures reveal no discernible trend: for example, the numbers of admissions for children and teenagers for 1840-1849 was 181, and for 1890-1899 it was 107 (and incidentally, it was 113 between 1784 and 1794, when the total intake was far smaller).

Dr Hare argues that descriptions of recognisably schizophrenic symptoms are difficult to find at the beginning of the 19th century, and that the major signs, "thought disorder, flatness of affect, loss of initiative - are not only hard to assess, but in the absence of an accepted terminology would be hard to describe". This is, again, to ignore the work of Haslam, one of the few authors on insanity at this time who had much direct experience of the subject. "... there is a form of insanity which occurs in young persons ... The sensibility appears to be considerably blunted; they do not bear the same affection towards their parents and relations; they become unfeeling to kindness, and careless of reproof ... As their apathy increases they are negligent of their dress, and inattentive to personal cleanliness. Frequently they seem to experience transient impulses of passion, but these have no source in sentiment; the tears which trickle down at one time, are as 
unmeaning as the loud laugh which succeeds them". (Haslam, 1809).

Haslam also refers to the frequency of auditory hallucinations among the insane, and elsewhere he devotes an entire book to the study of a patient admitted to Bethlem in 1797 with what appear to be classic symptoms of schizophrenic thought disorder (Haslam, 1810). What is important about all these descriptions of schizophrenia-like symptoms is that he writes of them as though they were nothing new: indeed, as though they were so common, obvious, and typical that it is scarcely surprising that most authors found them hardly worth mentioning, at a time before interest in phenomenology had developed, and when they had few opportunities for observation anyway.

The purpose of the evidence presented here is not to disprove the 'recency' hypothesis: our aim is rather to suggest that the historical reasoning it relies on is often dubious. The importance of Dr Hare's work is to raise issues which are important to modern psychiatry, while demonstrating how essential historical knowledge is to the debate. The history of psychiatry is too important to be left entirely to historians ignorant of clinical issues, or psychiatrists unqualified to evaluate historical evidence. As there can be few practitioners trained in both disciplines, we would plead for more active co-operation between the two.

Rajendra D. Persaud

The Bethlem Royal Hospital and

Patricia H. Allderidge

The Maudsley Hospital

Monks Orchard Road

Beckenham

Kent BR3 3BX

\section{References}

HARPER, A. (1789) A Treatise on the Real Cause and Care of Insanity. London: Stalker.

HASLAM, J. (1809) Observations on Melancholy and Madness, pp 64-66. London: Callow.

- (1810) Illustrations of Madness. London: Rivington et al.

WILKINs, R. (1987) Hallucinations in children and teenagers admitted to Bethlem Hospital in the nineteenth century and their possible relevance to the incidence of schizophrenia. Journal of Child Psychology and Psychiatry, 28, 569-580.

\section{Repetition of parasuicide}

SIR: We studied the repetition of parasuicide in Edinburgh in the period 1980-1981 (Wilkinson \& Smeeton, 1987), and so read with interest the report by Kreitman \& Casey (Journal, December 1988, 792 800 ). We are puzzled as to why the authors based their categories of 'first-evers', 'minor repeaters' and 'grand repeaters' on the individual lifetime history of parasuicidal episodes. Given a stable pattern of parasuicide with respect to each cohort, more major repeaters are to be expected among older individuals, since they have been at longer risk of having an episode. This obser ration can be seen in Table II of their paper, up to the age of 34 . Results for different agegroups would be made more comparable by assessing the patient on a recent fixed period of time (say two years), as in our recent study of parasuicide repetition (Smeeton \& Wilkinson, 1988a).

Incidently, the fact that there are relatively few major repeaters over 35 years of age seems to indicate that these individuals had episodes of parasuicide much less frequently in their youth than the present generation of young repeaters. In order to verify this trend one would have to check parasuicide records categorised by age over at least 30 years.

On the subject of prediction, we found that major repeaters (five or more episodes in 2 years) could be sub-divided into those with clustered and those with chronic patterns of parasuicides. Prediction should be much easier for those with a clustered pattern, since once one parasuicide is observed, a series will probably follow in the near future. In another type of clustering, episodes may occur around the same dates in consecutive years (Smeeton \& Wilkinson, 1988b). It would be particularly interesting to see how clinical and social problems are related in time to clusters of episodes.

With the possibility of the clustering of episodes in mind, the lifetime history seems a rather crude measure of current needs. It may be that some patients with a large number of prior episodes (Drs Kreitman \& Casey's major repeaters) are currently experiencing an untroubled period. Conversely, some of their minor repeaters may be commencing a period of frequent repetition and may be experiencing problems which are far from minor.

Nigel SMEETON GREG WILKINSON

General Practice Research Unit

Institute of Psychiatry

De Crespigny Park

Denmark Hill

London SE5 8AF

References

SMEETON, N. \& WiLxinson, G. (1988a) The identification of clustering in parasuicide. British Journal of Psychiatry, 153, 218-221.

$-\&-(1988 b)$ The detection of annual clusters in individual patterns of parasuicide. Journal of Applied Statistics, 15, 179-182.

WILKINSON, G. \& SMEETON, N. (1987) The repetition of parasuicide in Edinburgh 1980-1981. Social Psychiatry, 22, 14-19. 